\title{
Lack of Staphylococcal Enterotoxin Production among Strains of Staphylococcus aureus from Bovine Mastitis in Denmark
}

Staphylococcal enterotoxins (SE's) are a group of small exoproteins produced by some strains of Staphylococcus aureus. The SE's, designated A to $\mathrm{E}$ according to their antigenic specificities, are important causes of food poisoning worldwide. Milk and dairy products are frequently associated with $S$. aureus enterotoxin food poisoning, and it is supposed that infected milk from mastitic animals constitute the main source of enterotoxigenic $S$. aureus of animal origin (Bryon 1983, Gilmour \& Harvey 1990, Bergdoll 1989). Indeed, S. aureus is the most common cause of bovine mastitis worldwide, and if mastitis strains produce SE this makes up an enormous reservoir of potential enterotoxin producers. The production of SE by $S$. aureus isolated from bovine mastitis have been investigated in several countries (Matsunaga et al. 1993, Kenny et al. 1993, Olson et al. 1970, Orden et al. 1992, Olsvik et al. 1981, Adekeye 1980, Garcia et al. 1980, Abbar 1986, Harvey \& Gilmour 1985). Since no studies have been performed on the prevalence of enterotoxigenic strains of $S$. aureus isolated from bovine mastitis in Denmark, a well characterized collection of $S$. aureus ( $A a-$ restrup et al. 1995) was investigated with respect to this property.

One hundred and six isolates of $S$. aureus from clinical and subclinical cases of bovine mastitis from 106 Danish dairy farms were investigated. The strains belonged to a large number of different geno- and phenotypes. All strains were tested for production of SEA to SED by reverse passive latex agglutination with a commercial available kit (Oxoid, Wesel, Germany). As positive controls were included 3 SE-producing strains, ROS121 producing SEB and SED, FRED7 producing SEC and HORS2817 producing SEA. No attempt was made to test specifically for SEE, but as SEE is reported to cross-react with SEA, it should give positive results with SEA antisera (Lee et al. 1978).

None of the $106 \mathrm{~S}$. aureus strains from bovine mastitis produced SE, whereas the 3 positive controls gave positive reactions indicating appropriate test conditions and Kit-performance.

In order to estimate the true prevalence of a property among strains of a particular origin, it is important that the sample collected is representative for and randomly selected among the population studied. In this study strains isolated from different cases of bovine mastitis from different farms in Denmark and belonging to several different geno- and phenotypes were tested for their production of SE. None of the 106 strains studied produced SEA-D, and even though the collection is small this strongly indicates that this property is uncommon among strains of $S$. aureus isolated from bovine mastitis in Denmark. Furthermore, the results implies that production 
of SE is not associated with virulence for strains of $S$. aureus causing bovine mastitis. Other investigators have reported significantly higher prevalences of SE producing strains. Examination of 46 isolates for production of SEA-C in Norway in 1981 revealed that $32(69 \%)$ produced SE (Olsvik et al. 1981). However, there is no indication of whether all of these strains were from mastitic milk. In North America, Olson et al. (1970) examined strains from acute mastitis and Kenny et al. (1993) examined strains from mammary secretions and found $19 \%$ and $27 \%$ strains positive for production of SEA-D and A-E among 157 and 262 strains respectively. Matsunaga et al. (1993) found 34\% positive among 58 mastitis strains investigated for production of SEA-D in Japan. In studies of 50 strains of bovine origin for production of SEA-C and SEE from Nigeria, Adekeye (1980) found $12 \%$ positive, but it is not stated whether these strains are from milk. In studies of mastitis strains in Spain, Orden et al. (1992), Garcia et al. (1980) and Abbar et al. (1986) found $19 \%$ (A-E), 7\% (A-D) and 13\% (A-D) positive strains, respectively, among 26,57 and 45 strains investigated. In closer agreement with the present study were the studies by Lopes et al. (1990) in Brazil and Harvey \& Gilmour (1985) in Northern Ireland. In these latter studies, 127 and 56 mastitis strains were investigated for production of SEA-E, and $5 \%$ and $4 \%$ were positive, respectively. Thus, the percentage of SE producing strains of $S$. aureus from bovine mastitis have varied considerably among studies, which may be a reflection of differences in the extramammary reservoir in the various countries. SE production seems not to be associated with the capability of strains of $S$. aureus to cause bovine mastitis. The observations in this study indicate that mastitic milk does not constitute any large risk for $S$. aureus enterotoxin food poi- soning in Denmark. Contamination of milk or dairy products with SE producing strains of $S$. aureus might more commonly arise from human or animal carriers, but care should be taken to avoid any kind of contamination.

F. M. Aarestrup ${ }^{1}$, J. K. Andersen ${ }^{2}$ and N. E. Jensen ${ }^{1}$. ${ }^{1}$ Danish Veterinary Laboratory, Copenhagen, Denmark.

${ }^{2}$ National Food Agency of Denmark, Mørkhøj Bygade 19, 2860 Søborg, Denmark.

\section{References}

Aarestrup FM, Wegener HC, Rosdahl VT' Evaluation of phenotypic and genotypic methods for epıdemiological typing of Staphylococcus aureus isolates from bovine mastitis in Denmark. Vet. Microbiol. 1995. (In press).

Abbar FM, Mohammed MT, Arslain SH: Selected biological properties of enterotoxigenic staphylococc1 isolated from milk. J. Food Protect. 1986, 49, 871-873.

Adekeye D: Enterotoxin production by strains of Staphylococcus aureus isolated from animals and man in Nigeria. Vet. Microbiol. 1980, 5, 143150.

Bergdoll MS: Staphylococcus aureus In: Doyle MP (ed.). Foodborne bacterial pathogens, Marcel Dekker, New York and Basel. 1989, pp. 463-523.

Bryon FL. Epidemiology of milk-borne diseases. J. Food Protect. 1983, 46, 637-649.

Garcia ML, Moreno B, Bergdoll MS . Characterization of staphylococci isolated from mastitic cows in Spain. Appl. environ. Microbıol. 1980, 39, 548553.

Gulmour A, Harvey J: Staphylococcı in milk and milk products. In: Jones D, Board RC (eds.). Staphylococci. Soc. Appl. Bacteriol. Symp. 1990, Suppl. 69, 1475-1665.

Harvey J, Gilmour A: Application of current methods for isolation and identification of staphylococci in raw bovine milk. J. appl. Bacteriol. 1985, 59, 207-221

Kenny K, Reuser RF, Bastıda-Corcuera FD, Norcross $N L$ : Production of enterotoxıns and toxıc shock syndrome toxin by bovine mammary isolates of Staphylococcus aureus. J. cln. Microbiol. 1993, 31, 706-707. 
Lee A, Robbins RN, Bergdoll MS: Isolation of specific and common antibodies to staphylococcal enterotoxins $A$ and $E$ by affinity chrometography. Infect. Immun 1978, 21, 387-391.

Matsunaga T, Kamata S, Kakılchı N, Uchida K: Characterıstics of Staphylococcus aureus from peracute, acute and chronic bovine mastitıs. J. vet. med. Sci. 1993, 55, 297-300

Olson JC, Casman EP, Baer EF, Stone JE: Enterotoxigenicity of Staphylococcus aureus cultures isolated from acute cases of bovine mastitis. Appl. Microbiol. 1970, 20, 605-607.
Olsvlk $\emptyset$, Berdal BP, Fossum K, Omland T: Enterotoxin production by Staphylococcus aureus related to the origin of the strains Acta path. microbiol. scand. Sect. B, 1981, 89, 423-426.

Orden JA, Goyache J, Hernández J, Doménech A, Suárez G, Gómez-Lucia E · Detection of enterotoxins and TSST-1 secreted by Staphylococcus aureus isolated from ruminant mastitis. Comparison of ELISA and immunoblot J. appl. Bacteriol. 1992, 72, 486-489.

(Recelved January 12, 1995; accepted February 23, 1995).

Reprints may be requested from: F.M. Aarestrup, Danısh Veterınary Laboratory, Bulowsvej 27, DK-1790 Copenhagen, Denmark. 
